\title{
Influences of out-of-plane fiber waviness on the curved beam strength of glass fiber composite laminates
}

\author{
Düzlem dışı fiber dalgalanmasının cam elyaf takviyeli tabakalı \\ kompozitlerin kavisli kiriş dayanımı üzerindeki etkileri
}

\author{
Kenan ÇINAR ${ }^{1^{*} \text { iD }}$ \\ ${ }^{1}$ Department of Mechanical Engineering, Çorlu Engineering Faculty, Namık Kemal University, Tekirdag, Turkey. \\ kcinar@nku.edu.tr
}

Received/Geliș Tarihi: 08.10.2018, Accepted/Kabul Tarihi: 02.04.2019

doi: $10.5505 /$ pajes. 2019.52993

* Corresponding author/Yazıșllan Yazar Research Article/Araștırma Makalesi

\begin{abstract}
In-plane and out-of-plane waviness are inevitable defects in parts that have curved sections made of continuous fiber-reinforced composites. These defects can be located in the micro, meso (ply level) and macroscale (part level). In this study, an artificial out-of-plane fiber waviness was generated on the outer surface of the curved section of the L-shaped laminates. The fiber waviness generated was characterized experimentally using micrographs taken from the samples. The effect of fiber waviness on curved beam strength and delamination of the samples were determined through bending tests. Also, the effect of fiber waviness on the strain distribution on the curved section was quantified using Digital Image Correlation (DIC) technique.
\end{abstract}

Keywords: Fiber waviness, Digital image correlation (DIC), Defects, Bending testing, Glass fibers

\section{Introduction}

Continuous fiber reinforced composite materials have seen a rapid rise in commercial applications in aerospace, automotive, and marine industries due to new regulations and standards regarding fuel consumption, in addition to their superior properties of high stiffness to weight ratio. Complex part shapes used in the production line of these industries results in fiber waviness (in-plane and out-of-plane) and wrinkling (buckling of plies in the through-thickness direction) defects especially in the curved section of the parts. These kind of defects occur in continuous fiber reinforced composites during forming and consolidation step. During lay-up process the stack of plies and fabrics is consolidated using vacuum pressure to remove air trapped between plies and fabric layers. Through debulking process, plies and fabrics are forced to seat on the imposed tool surface. For instance, for male mold, the outermost ply or fabric is forced into a tighter geometry. If the layers cannot shear relative to each other, there axial compression forces on the layers occur, which may cause wrinkles. Wrinkling of plies in the through-thickness direction is schematically shown in Figure $1(a$ and $b$ ).

The mechanism of forming induced fiber wrinkling and waviness have been investigated and characterized for prepreg based material [1]-[6], biaxial woven fabrics [7]-[11] and noncrimp fabrics [12]-[15]. Slip layer between tool and the first ply [1] and interply slippage during the bending [3],[5] was the main mechanisms that results in fiber wrinkling in prepreg based material in the production of U-shaped components. Lightfoot et al. [1] found that increasing surface tool surface
Öz

Düzlem içi ve düzlem dıșı dalgalanma, sürekli fiber takviyeli kompozitlerden yapılmıș kavisli bölgelere sahip parçalarda kaçınılmaz kusurlardır. Bu kusurlar mikro, mezo (katman seviyesi) ve makro ölçekli (parça seviyesi) olabilir. Bu çalıșmada, L șekilli laminatların kavisli bölümünün dış yüzeyinde yapay bir düzlem dışı fiber dalgası olușturulmuștur. Elde edilen fiber dalgalanmalarl, numunelerden alınan mikrogörüntüler kullanılarak deneysel olarak karakterize edilmiștir. Fiber dalgalanmaların kavisli kiriș mukavemeti ve numunelerin delaminasyonuna etkisi eğme testleri ile belirlenmistir Ayrıca, fiber dalgalanmasının eğri kesitteki birim şekil değiștirme dağılımına etkisi Sayısal Görüntü Korelasyonu (SGK) tekniği kullanılarak ölçülmüştür.

Anahtar kelimeler: Fiber dalgalanması, Sayısal görüntü Korelasyonu (SGK), Kusurlar, Eğilme testi, Cam fiberler

friction through the removal of release film from the tool surface eliminate the wrinkles. In addition, Hallender et al. [3],[5] investigated the effect of stacking sequence, ply thickness, and inter-ply friction on the formation of fiber wrinkling. It has been established that the stacking sequence has a dominant effect on the formation of fiber wrinkling. In some applications, a ply drop or addition may be essential for design considerations, which may result in fiber wrinkling defects [10]. For the biaxial woven fabrics, a high friction coefficient between tows and interply interactions is responsible for the wrinkle formation [8]. It was shown in the study of Potter et al. [10] that when a plain weave fabric lay down on the on the outside corner of a simple L section mold, fabric on the corner region is highly distorted due to the excess length generated by in-plane curvatures.

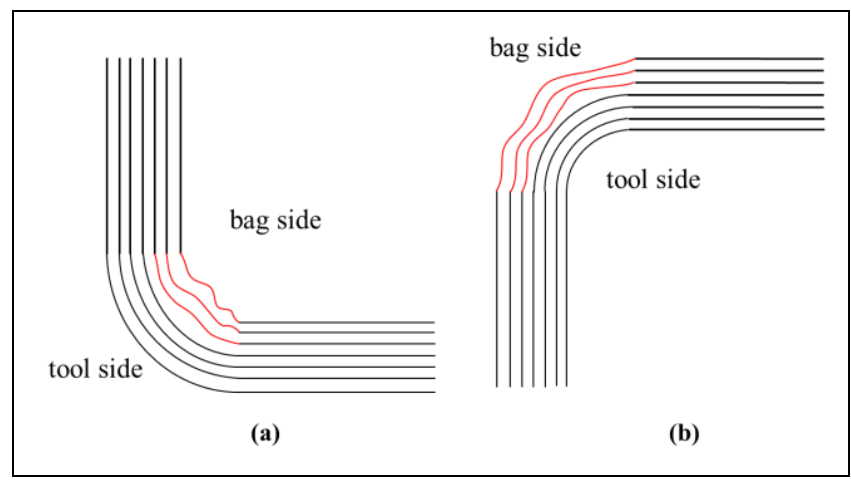

Figure 1(a): Wrinkling using female mold. (b): Wrinkling using male mold. 
A blank holder is applied to fabric preforms, which imposes a tension and reduces the wrinkle formation in the woven and non-crimp fabrics [12]. However, it cannot be used for every tooling design.

Defects such as fiber waviness and fiber wrinkling cannot be entirely eliminated. Therefore, the influence of fiber waviness and wrinkling on the mechanical properties of the parts should be considered. Many studies were conducted to establish an appropriate manufacturing technique to generate artificial inplane fiber waviness [16]-[23], and out-of-plane fiber waviness $[16],[17],[24]-[30]$ and to measure the degradation ratio of the mechanical properties. Wang et al. [24] developed the transverse strip method and the ply-drop method for the outof-plane waviness. Placing a thin rod at the interface between plies was another frequently used method to generate in-plane and out-of-plane fiber waviness [17],[27]-[29]. In order to generate out-of-plane waviness, Hasiao and Daniel [22] and Allison et al. [25] stacked plies that were pre-cured on curved mold between plies pre-cured on flat mold, thus, local out-ofplane fiber waviness were obtained between the flat plies. A similar method was used by [19] but they just considered the pre-cured plies on the curved mold. In-plane fiber waviness was obtained by flattening the pre-cured plies between two plates. Cinar and Ersoy [23] used the reverse technique in [19]. First, prepreg plies were laid down on a flat mold, and then the stacked plies pressed into L-shaped mold causing the fibers on the inner side to buckle. Wu et al. [17] measured the effect of inplane and out-of-plane fiber waviness on tensile, compressive, and impact properties of the flat laminate. It was found that both in-plane and out-of-plane waviness significantly reduced the compressive properties. For the case of out-of-plane waviness (waviness ratio of 0.04 ), a maximum reduction of $33.0 \%$ and $14.4 \%$ was observed in the compressive strength and the compressive modulus, respectively. The tensile strength and tensile modulus deceased a comparatively low extent as the waviness ratio increased in the both case of inplane waviness and out-of-plane waviness. On the other hand, out-of-plane waviness improved the impact strength. Hsiao and Daniel [22] found that fiber waviness ratio of 0.05 resulted in a $35 \%$ reduction in the compressive strength of S-glass/epoxy composites. Allison and Evans [25] measured the flexural strength of the laminates that have out-of-plane waviness. A $59.0 \%$ reduction in flexural strength was observed for the largest wave tested. It was also observed that the strength reduction depends on the location of the waviness; tension side or compression side. Wrinkles on the tension side influenced more significantly the strength reduction [10],[25]. The effect of fiber waviness on the fatigue life of composites was evaluated in the study of Hörrmann et al. [27]. It was shown that out-ofplane waviness has a severe influence on the fatigue life of the laminates and the fatigue life is reduced to approximately $50.0 \%$ of the reference laminate.

This study aims to observe the influence of out-of-plane waviness on the curve beam strength of the L-shaped glass fiber reinforced composite laminates. Vacuum Assisted Resin Infusion Transfer Molding (VARTM) was used to manufacture the laminates. Thin metal rods were used to generate out-ofplane waviness on the outer side of the corner section of the laminates. A series of four-point bending test were performed on the manufactured samples according to ASTM D6415/D, which is the standard test method for measuring the curved beam strength of fiber reinforced composites. DIC technique was considered during the bending test to quantify the internal strain and displacement fields. The deviation of the arcs on the inner and outer edge of the corner section was also evaluated during the bending tests.

\section{Materials and manufacturing procedures}

A typical non-crimp [0/-45/45/90] Quadriaxial E-glass fabric with a conventional epoxy resin system MGS R285/H285 was chosen as the material of the L-shaped laminates. The properties of the reinforcement material and the epoxy system are given in Table 1.

Table 1: The material properties of E-glass fabric and cured resin.

\begin{tabular}{cc}
\hline \multicolumn{2}{c}{ Cured resin (MGS R285/H285) [31] } \\
\hline Properties & Values \\
\hline Tensile strength, Syt (MPa) & $70-80$ \\
Compressive strength, $S_{\mathrm{yc}}(\mathrm{MPa})$ & $120-140$ \\
Elastic modulus, Em (GPa) & 3.2 \\
Poisson's ratio, $v_{\mathrm{m}}$ & 0.36 \\
Shear modulus, $\mathrm{G}_{\mathrm{m}}(\mathrm{GPa})$ & 1.18 \\
\hline The material properties of the fiber [32] \\
\hline Elastic modulus, Ef $(\mathrm{GPa})$ & 72.4 \\
Poisson's ratio, $v_{\mathrm{f}}$ & 0.22 \\
Shear modulus, Gf $(\mathrm{GPa})$ & 26.2 \\
\hline
\end{tabular}

A steel mold was manufactured to fabricate the samples on. The shape of the mold is shown in Figure 2(a). The angle between the arms and a radius at the bend are $90^{\circ}$ and $6.4 \mathrm{~mm}$, respectively.

Two kinds of L-shaped curved beam with and without out-ofplane waviness were manufactured with five replications. The number of plies was 24 which corresponds to a total thickness of $3.14 \mathrm{~mm}$ and the stacking sequence was $[0 /-45 / 45 / 90] 3 \mathrm{~s}$. The fiber volume fraction was measured at the arms of specimens and its value was $47.8 \%$ for both configurations.

A regular vacuum assisted resin transfer molding technique was used to manufacture the samples. Vacuum of approximately -0.9 bar was applied after laying all fabrics. All samples were cured at room temperature for 24 hours. However, it should be noted that a $3 \mathrm{~mm}$ silicone sheet was applied on the flowing mesh under the vacuum bag, which enables the fabrics to conform to the shape of the mold at the curved section. It was observed that large uncontrollable wrinkles occur at the curved section if the silicone sheet is not used. The silicone sheet was considered for the manufacturing of both laminates with and without fiber waviness. In order to generate out-of-plane fiber waviness on the outer surface of the curved region, two metal rods were stuck on the silicone sheet using strong double sided tape and this sheet laid-up on the flowing mesh under the vacuum bag, as shown in Figure 2(b and c). The manufacturing lay-up of the samples including fiber waviness is shown in Figure 2(c).

The manufactured L-shaped laminates with and without out-ofplane fiber waviness are shown in Figure 3(a). The L-shaped panel manufactured was then cut into five test specimens with a width of $25 \mathrm{~mm}$ each using a water cooled diamond disc cutter. The arms of the laminates were $100 \mathrm{~mm}$ and the angle between the arms was $90^{\circ}$, as shown in Figure 4. The samples without waviness and with out-of-plane fiber waviness are designated as a reference sample (RF-S_) and a waviness sample (W-S_). 


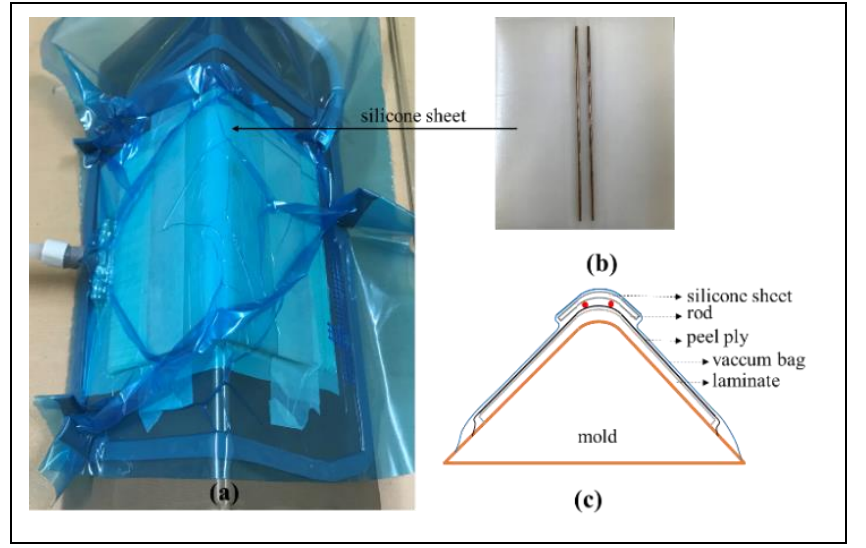

Figure 2(a): VARTM set-up. (b): Metal rods placed on the silicone sheet using double sided tape, and (c): schematic representation of the lay-up.

The waviness generated on the laminates was quantified using micrographs and a post-processing tool, Image J software. First, the images were imported into the Image J software and a conversion between image pixels and millimeters was performed using the known thickness of the laminates. Then, the coordinates of the points on the outer edge of the curved section were collected on the software. The data points are shown in Figure 3(a). Finally, a curve was fitted to the data points. The equation and the graph of the equation in polar coordinates determined from the micrographs are represented in Figure 3(b) for both laminates with and without out-of-plane fiber waviness. In future work, the determined equation will be used to generate a model for numerical analysis.

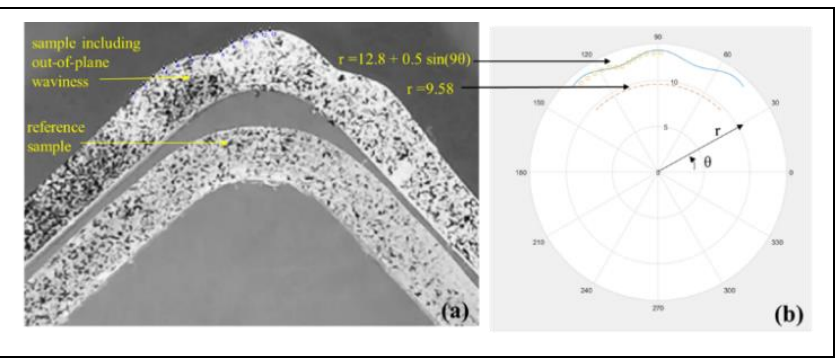

Figure 3(a): Manufactured samples, and (b): graph of waviness in polar coordinates.

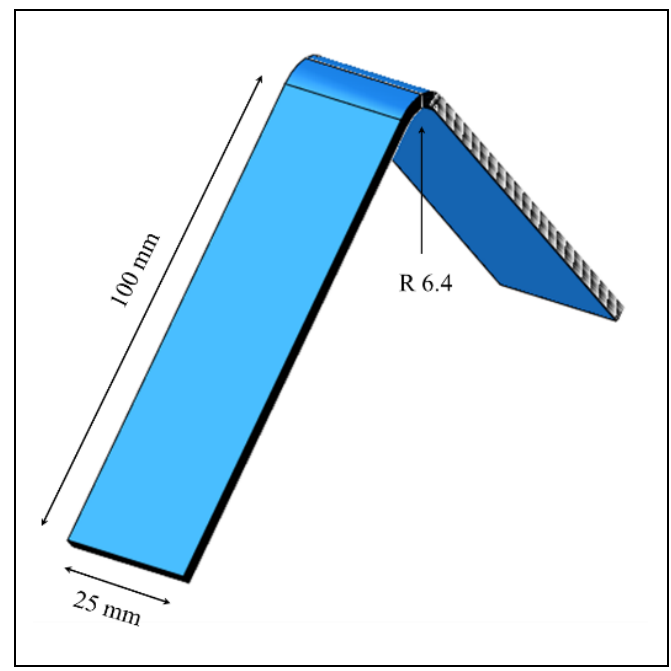

Figure 4: Dimensions of a sample.

\section{Bending tests}

A $100 \mathrm{kN}$ ALSA hydraulic tensile testing machine with fourpoint bending test setup was used for the bending tests, as shown in Figure 5. The testing machine was controlled by a computer and the head displacement rate was $2 \mathrm{~mm} / \mathrm{min}$. The testing methodology was based on ASTM D6415, which determines the Curved Beam Strength (CBS) of a continuous fiber reinforced composite materials. The L-shaped samples are comprised of two perpendicular straight arms connected by a $90^{\circ}$ curve. The length of the arms and the width were $100 \mathrm{~mm}$ and $25 \mathrm{~mm}$, respectively. The laminates are self-aligned under the test setup due the shape of the laminates. The span length of upper rollers and lower rollers were $35 \mathrm{~mm}$ and $65 \mathrm{~mm}$, respectively. Digital Image Correlation (DIC) technique was performed to quantify the displacement and strain field through the thickness of the laminates at the curved region. The specimen surfaces were prepared for DIC by coating the surface in black paint, which enabled pattern matching between image pairs. A 12 MP camera with a resolution of 1920x1080 was used to capture images. The image recording rate was 30 images per second. GOM correlate software was used in order to reveal and analyze the strain and displacement field. Overlapping quadratic subsets with the size of 37 pixels and a step of 14 pixels between two subsets and bicubic subpixel interpolation were parameters set in the software.

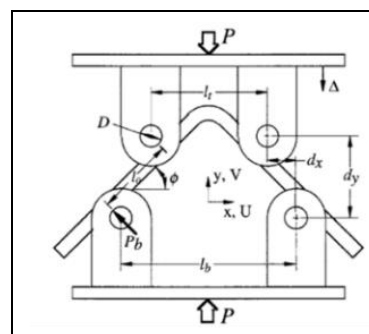

(a)

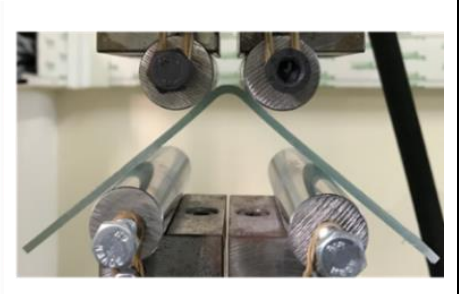

(b)
Figure 5(a): Schematic representation of test setup [33]. (b): Four-point bending test set-up.

\section{Results and discussion}

Figure 6 shows the load-displacement behavior of the laminates with and without out-of-plane fiber waviness under four-point bending. Black lines represent the behavior of the laminates without fiber waviness and red lines represent the behavior of the laminates with the included out-of-plane fiber waviness. Each test was repeated three times. The laminates without waviness sustained more load than those with waviness. As expected, the out-of-plane waviness decreased the load carrying capacity of the laminates. It was also observed that the slope of the load-displacement curves belonging to the samples without waviness was higher than the samples with waviness, which is likely a result of the waviness on the compression side of the beam. The tests were ended after abrupt delamination failure occurred at the curved section of the laminates.

The curved beam strength was calculated using the following formula in Eq. 1[33];

$$
C B S=\left(\frac{P}{2 w \cos \emptyset}\right)\left(\frac{d_{x}}{\cos \emptyset}+(D+t) \tan \emptyset\right)
$$

where $P$ is the ultimate load, $w$ is the width of the sample, $\emptyset$ is the angle in degrees of the loading arm from horizontal, $d_{x}$ is the horizontal distance between the centerlines of two top and 
bottom adjacent rollers, $D$ is the diameter of the rollers, $t$ is the thickness of the specimen. $C B S$ values calculated for each specimen are given in Table 2 . The average $C B S$ calculated using Eq. 1 for the laminates with and without fiber waviness was $752.14 \mathrm{~N} . \mathrm{mm} / \mathrm{mm}$ and $1213.00 \mathrm{~N} . \mathrm{mm} / \mathrm{mm}$, respectively. The out-of-plane waviness reduced the curved beam strength about $37.99 \%$.

Table 2: CBS values calculated for each specimen.

\begin{tabular}{cccc}
\hline & $\begin{array}{c}\text { CBS } \\
\text { (N.mm/mm) }\end{array}$ & & $\begin{array}{c}\text { CBS } \\
\text { (N.mm/mm) }\end{array}$ \\
\hline RF-S1 & 1258.89 & W-S1 & 754.14 \\
RF-S2 & 1215.00 & W-S2 & 754.16 \\
RF-S3 & 1165.12 & W-S3 & 748.15 \\
Average & 1213.00 & Average & 752.14 \\
Std. Deviation & 38.31 & Std. Deviation & 2.83 \\
\hline
\end{tabular}

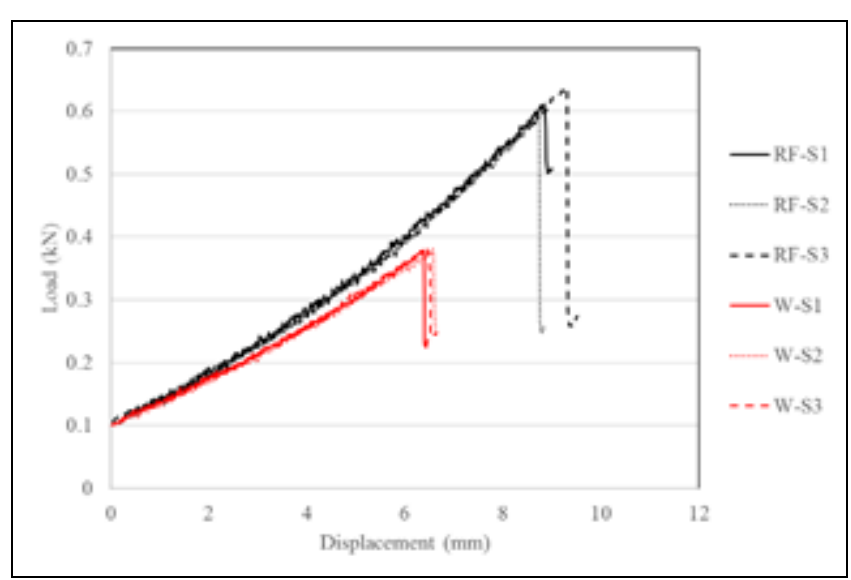

Figure 6: Load-displacement curves for both type of samples with and without fiber waviness.

The bright white regions on the laminates of Figure 7, indicate regions of delamination failure. The circumferential area of the delamination was calculated using the micrographs and it was found that larger delamination regions were observed in laminates without fiber waviness as compared to the laminates with fiber waviness. This result can be explained through the load-displacement curves. Laminates without fiber waviness experienced a higher load at the time of abrupt failure and therefore resulted in a larger delamination region.

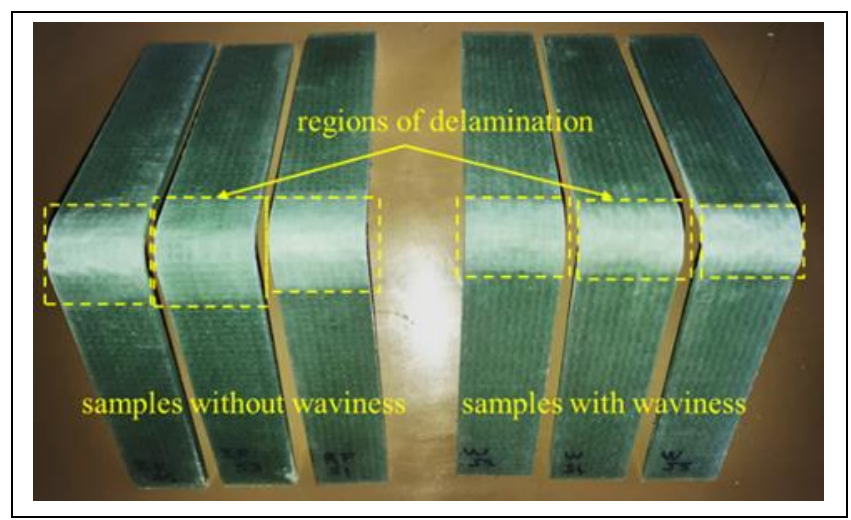

Figure 7: Region of delamination for reference samples (left), and samples including out-of-plane waviness (right).

The change in arc lengths of the samples were quantified using DIC technique. Six sections through the thickness were used to measure the change in arc lengths. For comparison purposes, the change in arc lengths were divided by their initial length. Figure 8 shows the change in arc length over initial length versus cross head displacement through thickness for both samples with waviness (Figure 8(a)), and without waviness (Figure 8(b)). The neutral axis was determined where the arc length does not change, and shown using black dotted lines in the figures. The extension of the arc at the inner region is higher than the contraction of the arc at the outer region for both samples but this phenomenon is more apparent for samples with fiber waviness. The extension is approximately 2.5 times higher than the contraction for the waviness case and implies that the value of extension and contraction with respect to neutral axis is not symmetric for the samples including fiber waviness. The contraction of arc length at the outer region is small due to local bending at the wave section for the samples with fiber waviness. The extension and contraction in the arc lengths is higher for the samples without fiber waviness than for the samples with fiber waviness before failure because the time of the failure is short for the samples with fiber waviness, as shown in Figure 6.

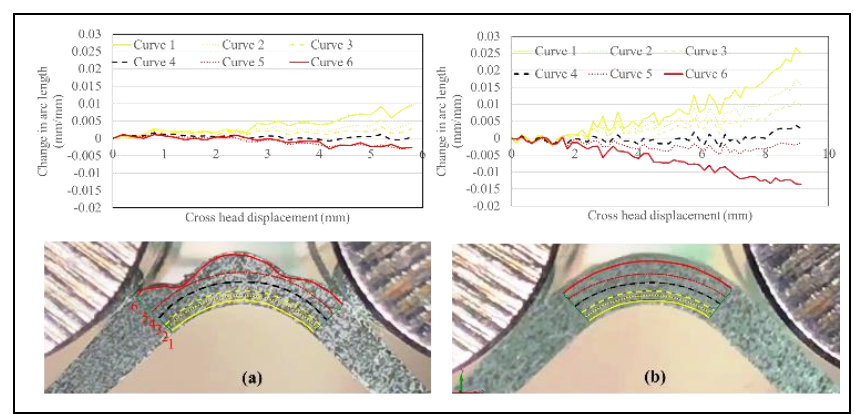

Figure 8(a): The change in arc lengths through thickness during bending of the samples with out of plane waviness.

(b): The change in arc lengths through thickness during bending of the samples without out of plane waviness.

Figure 9 shows a photomicrograph captured from the curved section of a reference sample. Each layer was represented using different color to distinguish resin rich regions. It was observed that most of the resin rich regions (orange regions) occur near the 90 -degree layers represented by yellow color and especially at the symmetry line.

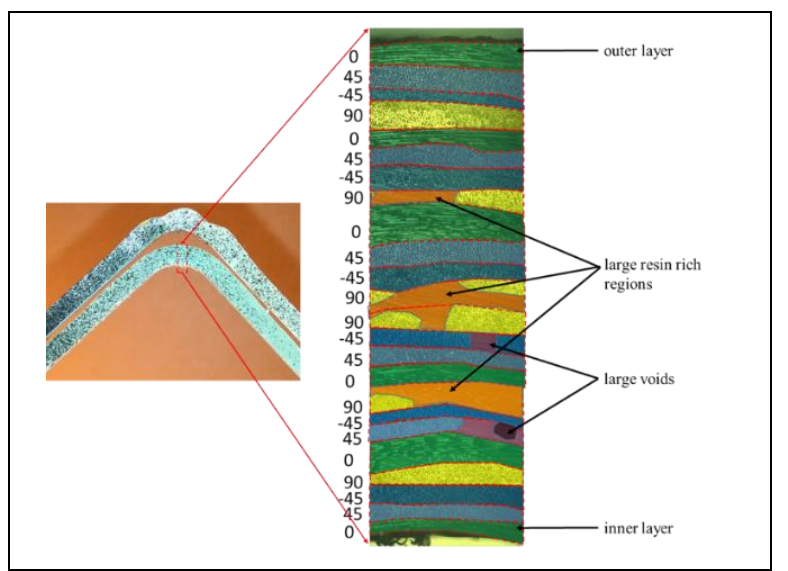

Figure 9: Photomicrograph of the reference sample captured from the curved section and its stacking sequence.

Figure $10(\mathrm{a})$ shows the normal strain field $\left(\varepsilon_{y y}\right)$ along $\mathrm{y}$ direction with respect to cross head displacement during the 
bending tests of a sample including fiber waviness. Normal strain field in y-direction also corresponds to radial strain field in y-direction. There was no significant change in the strain field up until the damage occurred. Sudden failure occurred at the displacement of $6.3 \mathrm{~mm}$ and the delamination region can be seen in the figure where higher strain is observed. Figure 10(b) shows a delamination pattern which matches DIC results. The delamination pattern was determined using photomicrograph captured from the samples. In order to show all of the delamination patterns, multiple photomicrograph was captured and joined together. The red dotted line represents the delamination pattern as shown in Figure 10(b). A back light source was used to differentiate the 90-degree layers from the other layers. Fiber bundles from 90-degree layers reflect the back light and can be easily differentiated, as seen in yellow in Figure 10(b). Delamination occurred at the symmetry line between two adjacent 90-degree layers and it proceeded up to a point where it crossed the 90 -degree layer, -45 -degree, and 45-degree layers up to 0 -degree, respectively. When the photomicrographs (Figure 9) were examined, it was observed that resin rich regions were formed between $90^{\circ}$ fiber bundles. These $90^{\circ}$ fiber bundles overlap in the symmetry region so that larger resin packages are formed. It was thought that these resin rich regions caused delamination initiation. An intralaminar crack region where the crack traverses the 90degree layer can be seen in Figure 10(d).

Delamination pattern observed for the reference sample had more crack branching than the waviness case, as represented by the red dotted line in Figure 11(a). The reference sample sustained more load than the waviness one and therefore stored more energy. The higher energy released, increased the crack length. The delamination region for the reference sample was higher than the delamination region of the sample including waviness. The delamination region captured at the time of damage for the reference sample is shown in Figure 11(b). Delamination occurred at the symmetry line and the top of symmetry line between two adjacent -45-degree and 45-degree. Intralaminar crack region where the crack crosses 90-degree, -45-degree and 45-degree layers was observed similar to the waviness case. Crack cannot cross the 0 -degree layer for both cases. Figure 11(c) shows normal strain field in y direction. Similar to the waviness case, no significant strain occurred in y-direction prior to failure. Abrupt delamination failure occurred at the crosshead displacement of $9.3 \mathrm{~mm}$. As a result of the large delamination failure and the discontinuities associated, the strain field cannot be captured clearly at the failure time (displacement of $3 \mathrm{~mm}$ ).

\section{Conclusions}

In this study, an artificial out-of-plane fiber waviness was generated on the outer surface of the curved section of the Lshaped laminates using a vacuum assisted resin transfer molding processing method. A series of four-point bending test were performed on the manufactured samples with DIC technique to measure the curved beam strength of fiber reinforced composites.

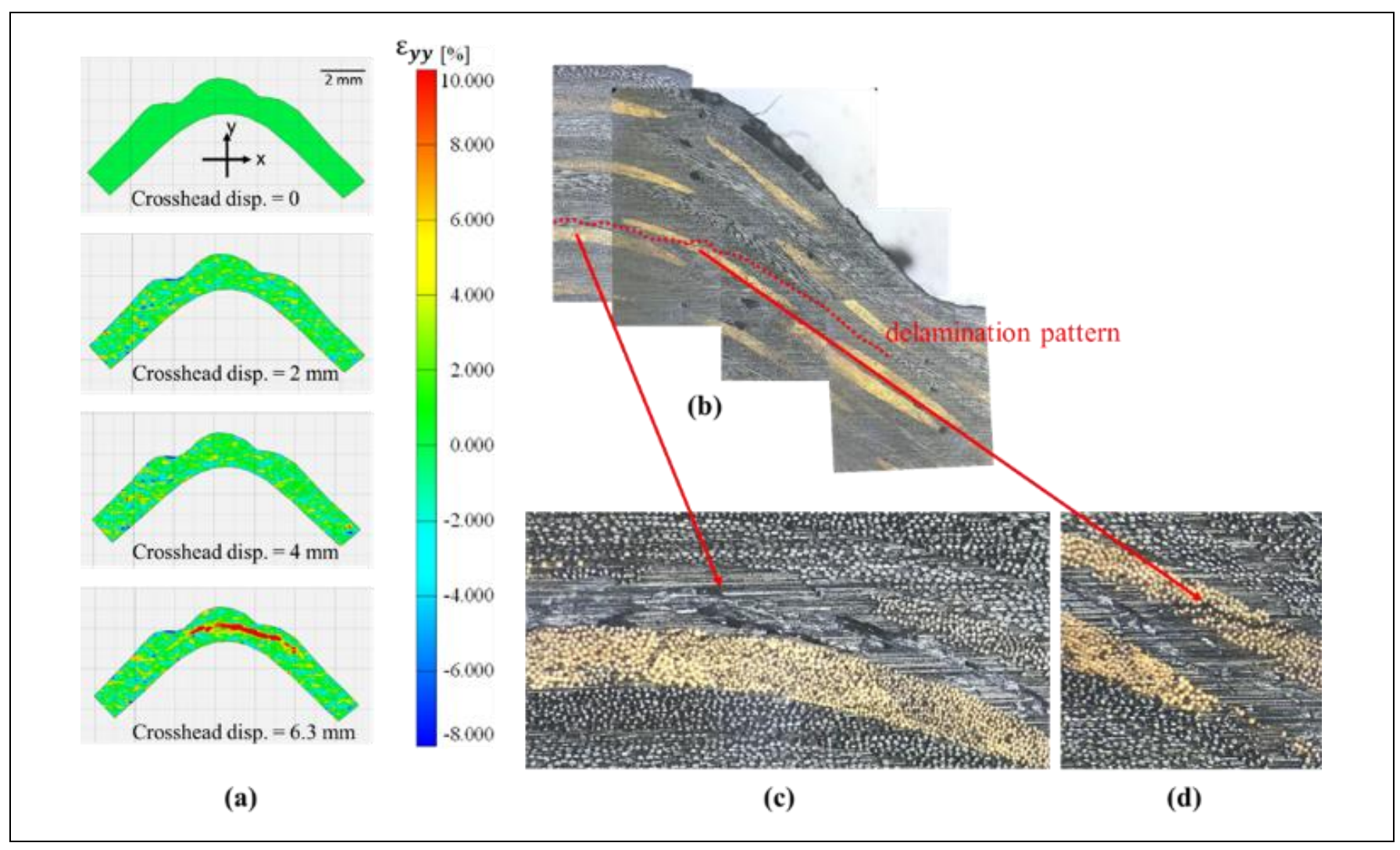

Figure 10(a): Normal strain field in y-direction with respect to crosshead displacement. (b): Representation of the delamination pattern. (c): Magnification of crack region between two 90-degree layers (symmetry line), and (d): Magnification of crack region where crack crosses 90-degree layer. 


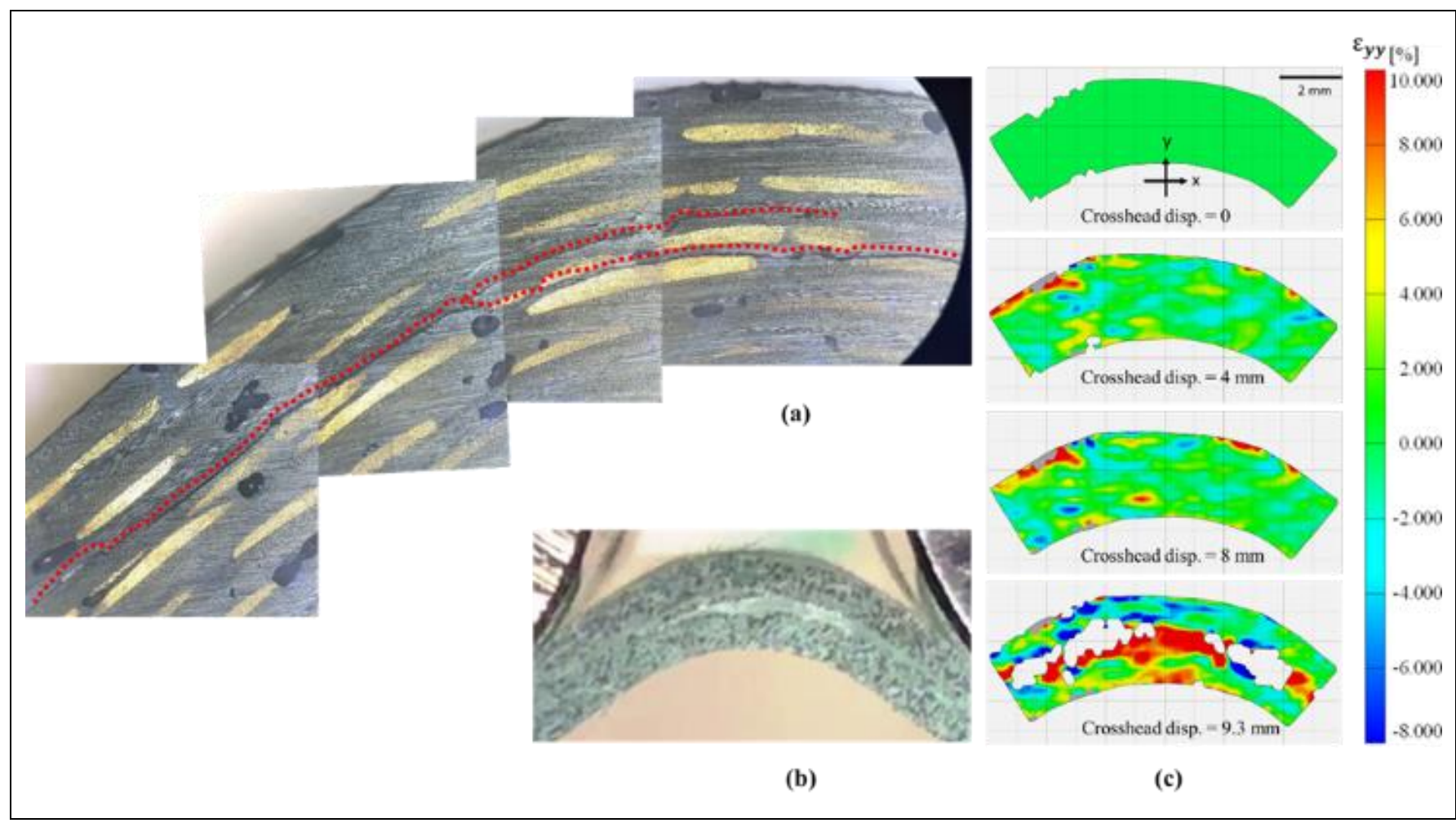

Figure 11(a): Representation of the delamination pattern. (b): The delamination region captured at the time of damage, and (c): Normal strain field in y-direction with respect to crosshead displacement.

The laminates without waviness sustained more load than the samples with fiber waviness. Out-of-plane waviness decreased the load carrying capacity of the laminates. It was also observed that the slope of the load-displacement curves belonging to the samples without waviness was higher than the samples with waviness.

The change in the arc lengths for both configuration was also measured using DIC technique and it was found that the extension of the arc at the inner region is higher than the contraction of the arc at the outer region for both samples. This phenomenon was more apparent for samples with fiber waviness. The extension was approximately 2.5 times higher than the contraction for the waviness case so that the value of extension and contraction with respect to neutral axis was not symmetric for the samples including fiber waviness.

Delamination pattern observed for the reference sample had more crack branching than the waviness case. This observation is attributed to the fact that the reference sample sustained higher load than the sample with containing defects and as a result had more strain energy at the time of failure. It was observed that the location of delaminated regions differed between the reference and defected samples. For samples containing the induced fiber waviness, delamination occurred at the symmetry line between two adjacent 90-degree layers. However, for the reference samples, delamination occurred at both the symmetry line and the top of the symmetry line between two adjacent -45-degree and 45-degree.

In order to decrease fiber wrinkling the radius of a corner should be larger as much as possible. Also, as applied in this study a silicone rubber can be used at the corners on the fabric to decrease wrinkling defects which is triggered by vacuum bag.

\section{Acknowledgments}

Kenan Cinar acknowledges the support of the Tekirdağ Namık Kemal University Research Fund under project code of NKUBAP.00.17.AR.15.03.

\section{References}

[1] Lightfoot J, Wisnom M, Potter K. "A new mechanism for the formation of ply wrinkles due to shear between plies". Composite Part A, 49, 139-147, 2013.

[2] Dodwell T, Butler R, Hunt G. "Out-of-plane ply wrinkling defects during consolidation over an external radius". Composite Science and Technology, 105, 151-159, 2014.

[3] Hallender P, Sjölander J, Akermo M. "Forming induced wrinkling of composite laminates with mixed ply material properties; an experimental study". Composite Part A, 78, 234-245, 2015

[4] Sjölander J, Hallander P, Akermo M. "Forming induced wrinkling of composite laminates: a numerical study on wrinkling mechanisms". Composite Part A, 81, 41-51, 2016.

[5] Hallander P, Akermo M, Mattei C, Petterson M, Nyman T. "An experimenatal study of mechanisms behind wrinkle development during forming of composite laminates". Composite Part A, 50, 54-64, 2013.

[6] Farnand K, Zobeiry N, Poursartip A, Fernlund G. "Microlevel mechanisms of fiber waviness and wrinkling during hot drape forming of unidirectional prepreg composites". Composites Part A, 103, 168-177, 2017.

[7] Tam A, Gutowski T. "The kinematics for forming ideal aligned fibre composites into complex shapes". Composites Manufacturing, 1(4), 219-228, 1990. 
[8] Prodromou AG, Chen J. "On the relationship between shear angle and wrinkling of textile composite preforms". Composite Part A, 28(5), 491-503, 1997.

[9] Harrison P, Abdiwi F, Guo Z, Potluri P, Yu W. "Characterising the shear-tension coupling and wrinkling behaviour of woven engineering fabrics". Composite Part A, 43(6), 903-914, 2012.

[10] Potter K, Khan B, Wisnom M, Bell T, Stevens J. "Variability, fibre waviness and misalignment in the determination of the properties of composite materials and structures". Composite Part A, 39(9), 1343-1354, 2008.

[11] Boisse P, Hamila N, Vidal-Salle E, Dumont F. "Simulation of wrinkling during textile composite reinforcement forming. Influence of tensile, in-plane shear and bending stiffnesses". Composites Science and Technology, 71, 683692, 2011.

[12] Lee J, Hang S, Yu W, Kang T. "The effect of blank holder force on the stamp forming behavior of non-crimp fabric with a chain stitch". Composite Science and Technology, 67(3), 357-366, 2007.

[13] Kong H, Mouritz A, Paton R. "Tensile extension properties and deformation mechanisms of multiaxial non-crimp fabrics". Composite Structures, 66(1), 249-259, 2004.

[14] Arnold S, Sutcliffe M, Oram W. "Experimental measurement of wrinkle formation during draping of noncrimp fabric". Composites Part A, 82, 159-169, 2016.

[15] Ferreira L, Graciani E, Paris F. "Modelling the waviness of the fibres in non-crimp fabric composites using 3D finite element models with straight tows". Composite Structures, 107, 79-87, 2014.

[16] Sutcliffe M, Lemanski S, Scott A. "Measurement of fiber waviness in industrial composite components". Composite Science and Technology, 72, 2016-2023, 2012.

[17] Wu C, Gu Y, Luo L, Xu P, Wang S, Li M, Zhang Z. "Influences of in-plane and out-of-plane fiber waviness on mechanical properties of carbon fiber composite laminate". Journal of Reinforced Plastics and Composites, 37(13), 877-891, 2018.

[18] Zhao C, Xiao J, Li Y, Chu Q, Xu T, Wang B. "An experimental study of the influence of in-plane fiber waviness on unidirectional laminates tensile properties". Applied Composite Materials, 24, 1321-1337, 2017.

[19] Christian W, DiazDelaO F, Atherton K, Patterson E. "An experimental study on the manufacture and characteriazation of in-plane fibre-waviness defects in composites". Royal Society Open Science, 5, 1-16, 2018.

[20] Mizukami K, Ogi K. "Non-contact visualization of fiber waviness distribution in carbon fiber composites using eddy current testing". Advanced Composite Materials, 27(2), 135-146, 2018.
[21] Nair S, Dasari A, Yue C, Narasimalu S. "Failure behaviour of unidirectional composites under compression loading:effect of fiber waviness". Materials, 10(8), 2017, doi:10.3390/ma10080909.

[22] Hasiao H, Daniel I. "Elastic properties of composites with fiber waviness". Composites Part A, 27, 931-941, 1996.

[23] Cinar K, Ersoy N. "Effect of fibre wrinkling to the spring-in behaviour of L-shaped composite materials". Composite Part A, 69, 105-114, 2015.

[24] Wang J, Potter K, Hazra K, Wisnom M. "Experimental fabrication and characterization of out-of-plane fiber waviness in continuous fiber-reinforced composites". Journal of Composite Materials, 46(17), 2041-2053, 2012.

[25] Allison B, Evans J. "Effect of fiber waviness on the bending behaviour of S-glass/epoxy composites". Materials and Design, 36, 316-322, 2012.

[26] Zhu J, Wang J, Zu L. "Influence of out-of-plane ply waviness on elastic properties of composite laminates under uniaxial loading". Composite Structures, 132, 440-450, 2015.

[27] Hörmann S, Adumitroaie A, Viechtbauer C, Schagerl M. "The effect of fiber waviness on the fatigue life of CFRP materials". International Journal of Fatigue, 90, 139-147, 2016.

[28] El-Hajjar R, Petersen D. "Gaussion function characterization of unnotched tension behaviour in a carbon/epoxy composite containing localized fiber waviness". Composite Structures, 93, 2400-2408, 2011.

[29] Elhajjar R, Shams S. "Compression testing of continuous fiber reinforced polymer composites with out-of-plane fiber waviness and circular notches". Polymer Testing, 35, 45-55, 2014.

[30] Nikishkov G, Nikishkov Y, Makeev A. "Finite element mesh generation for composites with ply waviness based on $\mathrm{x}$ ray computed tomography". Advances in Engineering Software, 58, 35-44, 2013.

[31] HEXION Specialty Chemicals. "Laminating Resin MGS L 285 Hardeners MGS 285-287 Technical data sheet". http://www.hexion.com/products/technicaldatasheet.as px?id=30303, (last accessed September 2016).

[32] Uzal A, Sonmez FO, Oz FE, Cinar K, Ersoy N. "A composite sandwich plate with a novel core design". Composite Structures, 193, 198-211, 2018.

[33] American Society for Testing and Materials International, "ASTM D6415, Standard test method for measuring the curved beam strength of a fiber-reinforced polymermatrix composite". West Conshohocken, PA, United States, 2013. 